\title{
Public Health Messages: Why Are They Ineffective and What Can Be Done?
}

\author{
Timothy P. Gill • Sinead Boylan
}

Published online: 25 January 2012

(C) Springer Science+Business Media, LLC 2012

\begin{abstract}
Addressing the widespread problem of obesity will require sustained public health action. Health education and communication has been a central component of successful action on tobacco, alcohol, road safety, and other public health issues. However, programs to address obesity that are largely based around health education alone have been unable to produce any significant improvements in body fatness. Obesity is a very complex condition that requires actions at many levels and within many sectors to enable the level of behavior change sufficient to positively influence weight status.
\end{abstract}

Keywords Obesity prevention $\cdot$ Public health $\cdot$ Health communication $\cdot$ Health education $\cdot$ Mass media $\cdot$ Public health messages

\section{Introduction}

Obesity results from a prolonged period of energy imbalance where the energy intake from food and drink exceeds energy expenditure for metabolic processes and physical activity. Although there has been substantial effort invested in identifying the major determinants of energy imbalance, we still have an incomplete understanding of the key drivers of obesity at both a personal and population level $[1 \bullet \bullet$.

\footnotetext{
T. P. Gill $(\bowtie) \cdot$ S. Boylan

Boden Institute of Obesity, Nutrition,

Exercise and Eating Disorders, University of Sydney,

Medical Foundation Building K25,

Sydney, NSW 2006 Australia

e-mail: t.gill@sydney.edu.au

S. Boylan

e-mail: sboylan@usyd.edu.au
}

However, it is clear that behavior change must be a major element of obesity management and prevention programs and, consequently, numerous initiatives for public health education have been developed to address the rising rates of overweight and obesity across the world [2]. Past public health campaigns with strong education components have contributed to reductions in coronary heart disease, cancers, and HIV infections in many developed nations [3]; however, evidence of success among obesity prevention campaigns is relatively scant at present. The fact that over 1 billion adults and $10 \%$ of children have been classified as overweight or obese globally [4] calls for a closer examination of obesity prevention campaigns. The aim of this current review is to examine the recent evidence evaluating the effectiveness of public health messages in preventing obesity and provide recommendations for future strategies. Although a variety of strategies, methods, and approaches exist, this current review will examine how current communication-, theory-, and settings-based strategies are fairing in getting the message across. These are summarized in Table 1 and examined in detail below.

\section{Communication Strategies}

Mass Media

Providing appropriate advice and information to the population is an important first step in addressing any health concern and most public health initiatives rely on mass media to achieve this objective. Mass media campaigns have primarily been aimed at raising awareness, providing knowledge, and changing attitudes, with the aim of contributing to potential behavior change [5]. Many countries have invested in obesity-related mass media campaigns to improve 
Table 1 Strategies involved in public health messaging: a summary of findings from obesity prevention

\begin{tabular}{|c|c|}
\hline Strategies & Summary of findings \\
\hline \multicolumn{2}{|c|}{ Communication format } \\
\hline Mass media & $\begin{array}{l}\text { - Capacity to reach large audiences } \\
\text { - Programs evaluate impact on health knowledge and awareness rather than impact on weight } \\
\text { - Difficult to evaluate }\end{array}$ \\
\hline New media & $\begin{array}{l}\text { - Web-based programs are difficult to evaluate due to the heterogeneity of studies } \\
\text { - Evaluations of programs involving new communication technologies are limited } \\
\text { - Disadvantaged groups may not have access to new communication technologies }\end{array}$ \\
\hline Point-of purchase & $\begin{array}{l}\text { - Provides a lot of opportunity for intervention } \\
\text { - Most evaluations restricted to outcomes such as purchase behaviors and sales }\end{array}$ \\
\hline \multicolumn{2}{|l|}{ Settings-based } \\
\hline Early life & $\begin{array}{l}\text { - Research is in its early stages } \\
\text { - Potential/relatively unexplored interventions: preconception lifestyle, pregnancy/maternal diet, early infant diet } \\
\text { and feeding practices, early childcare services } \\
\text { - Strong evidence for breastfeeding promotion programs }\end{array}$ \\
\hline School & $\begin{array}{l}\text { - Favorable outcomes reported in terms of improved nutrition and physical activity; however, most studies } \\
\text { were of short duration and may not have been sustained for a sufficient period to impact on weight } \\
\text { - Multicomponent strategies aimed at targeting specific behaviors are encouraged }\end{array}$ \\
\hline Workplace & $\begin{array}{l}\text { - Drawing conclusions is difficult due to heterogeneity of studies and generalizability of programs is questionable } \\
\text { - Individual-level interventions appeared to deliver slightly greater effects on dietary behavior than environmental } \\
\text { interventions; however, educational approaches alone had a lower impact on weight than those that added } \\
\text { behavioral counseling }\end{array}$ \\
\hline Health care & $\begin{array}{l}\text { - Underdeveloped area of research, yet promising results from interventions regarding positive changes in dietary } \\
\text { and physical activity behavior and weight loss } \\
\text { - Intervention follow-up periods are generally of short duration } \\
\text { - Encourages more collaborative interventions to coordinate multicomponent interventions }\end{array}$ \\
\hline Community & $\begin{array}{l}\text { - Little evidence of successful weight gain prevention } \\
\text { - Disadvantaged groups are the focus of many targeted interventions, however although some strategies show } \\
\text { some promise (eg, cooking skills, community gardens), there is a lack of evidence of their effect on weight } \\
\text { - Evaluation of community programs is difficult to conduct due to their diversity and the time required to } \\
\text { develop such interventions }\end{array}$ \\
\hline
\end{tabular}

diet and physical activity; however, there is little data on their effectiveness as they are often not evaluated. Those who do evaluate campaigns usually do so within 1 year of the campaign, which does not provide a long enough time frame to identify any impact on community weight status. However, as aforementioned, mass media campaigns primarily aim to influence behavior change and so the majority of programs evaluate knowledge, awareness or attitude shift, or the process. Mass media is considered the best vehicle to initiate community mobilization because of its the capacity to reach large audiences quickly and efficiently [6] but its ability to achieve weight-related behavior changes may be limited. Therefore, health professionals are seeking more innovative channels to promote behavior change. But developing and evaluating the effectiveness of strategies is difficult to undertake at a population level; therefore, interventions are often designed to reach specific population groups or segments [7]. For this reason, the evaluation of health education in obesity prevention relies heavily on intervention studies and the results of such studies form the bulk of the evidence presented in this current review.

\section{New Media}

The rapid emergence of new communication technologies and new uses of older technologies, such as the telephone, provide new opportunities in getting the message across. Recent reviews of web-based intervention studies suggest that web-based interventions may be an effective means to facilitate weight loss; however, there has been little evaluation of the effectiveness of such interventions on weight gain prevention or weight maintenance $[8,9]$. These reviews also highlight the difficulty in fully assessing the effectiveness of web-based interventions due to the heterogeneity of study designs. The size of the impact of web-based programs on weight loss may be very limited. The results of a metaanalysis found that web-based interventions actually achieve similar weight loss to control or minimal intervention groups 
[9]. But further examination of intervention components showed that web-based interventions with enhanced features (eg, counseling, feedback) achieve greater weight loss than those with education alone. Caution is warranted in interpretation of these results, however, as the three studies included in this meta-analysis were from the same research group questioning the validity of the meta-analysis.

Mobile-phone technology is becoming an increasingly popular tool in monitoring healthy behavior; however, there has been little evaluation of its effectiveness on weight or weight-related behavior. New mobile phone applications for smart phones are released on a daily basis, but not everyone has access to this technology. Text messaging, conversely, is a form of communication that is usable on most handsets and is already very popular, especially among younger age groups. Although evaluations of interventions indicate that text messaging is a feasible way of improving knowledge and may promote weight loss, such interventions were generally of short duration and provided personalized advice and feedback, which may be difficult to reproduce at a population level [10-12]. Little is also known about the use of podcasting in promoting weight loss. Results from one trial found that the use of an enhanced podcast (based on social cognitive theory) was associated with improved knowledge and greater weight loss among adults compared with those who received the control podcast (discussions on how to lose weight). Again, this study was of short duration (12 weeks) and had a small sample size $(n=78)$ [13].

\section{Point-Of-Purchase Communication}

As the consumer must make several decisions at the pointof-purchase, there is a large window of opportunity to influence food choice using effective nutrition communication technologies. There have been a number of proposed strategies to address these issues and help prevent weight gain; however, evaluation of these strategies has produced mixed results and has been of weak methodology restricted to outcomes such as purchase intentions, purchase behaviors, and sales. Recent studies show that although education alone within food service settings and traffic light labeling fail to show an impact on food choice or sales [14, 15], supermarket shelf tags show a favorable impact on purchase intentions and behaviors [16].

Menu calorie posting has also been reported to have increased consumer awareness and healthy purchases, and results from a health impact assessment model suggest that $40.6 \%$ of the average weight gain in the US population could be averted using menu calorie labeling [17, 18]. On the contrary, other evidence indicates that calorie labeling is not well observed by consumers and that calorie labeling alone would not have an impact on obesity [19]. In 2008, regulations came into force in the city of New York requiring major fast food chains to provide calorie labeling of their products. The impact of these regulations was assessed by a recently published study that compared individual purchases 1 year before with those 9 months after its implementation [20•]. The mean calorie intake did not change over this period although a modest calorie reduction was seen when adjustments were made for some major confounders. In addition, significant changes were seen in consumption of calories within the three main restaurant chains.

\section{Settings-Based Strategies}

In recent years, there has been an increased focus on delivering health promotion programs within defined settings in which people live, work, and interact with on a daily basis rather than applying generic programs across the whole population. A settings approach has particular relevance to effective health education as each setting generally has existing communication systems for dissemination of targeted programs and provides channels for program delivery and access to specific populations [21]. A number of settings (early life, school, workplace, health care, and the community) have been utilized to address the issue of overweight and obesity and the evidence of the effectiveness of education interventions within such settings is assessed below.

\section{Early Life}

Recent research reveals that the early life period, comprising of preconception, in utero, infancy, and early childhood, is a critical period for the development of obesity [22]. As this area of research is in its infancy and the impact on weight and weight-related behaviors may take some time to achieve, there are limited evaluations of interventions in this area. Recent systematic reviews have examined the effect of lifestyle interventions in limiting excessive weight gain during pregnancy [23] or antenatal weight control [24] and found no consistent evidence that these interventions could lead to improved weight and health outcomes. Evidence from longitudinal studies also indicates that breastfeeding exposure and duration are associated with small but significant reductions in the development of childhood obesity and there is strong evidence supporting the effectiveness of breastfeeding promotion programs [25]. However, despite significant investment in programs to promote extended breastfeeding, there is little evidence that education alone is sufficient to significantly improve breastfeeding rates and duration. Strategies focusing on peer support and professional education proved more useful [26]. 


\section{School}

Schools provide a key setting for public health messages addressing the prevalence of overweight and obesity [27•] although their potential to effect behavior change is often overestimated. Children spend around $6 \mathrm{~h}$ at school each day, 40 weeks of the year, thus this setting provides significant opportunity to encourage consumption of healthy foods, regular physical activity, and teach lifelong skills for a healthy lifestyle. In addition, weight-related behaviors may be directly influenced by the school environment (eg, studies have related the availability of snacks and drinks sold in schools to students' high intake of total calories, soft drinks, total fat, and saturated fat, and lower intake of fruits and vegetables) $[27 \cdot]$.

School-based health programs often have a heavy reliance on education and many of the recently evaluated school-based programs show increased nutrition knowledge among students [28-32] and some show increased fruit and vegetable consumption [28, 32, 33]. However, the effectiveness or impact of school-based programs on body weight shows mixed results [30,33-36]. Most of these studies were of very short duration and therefore may have not have been sustained for a sufficient period to impact on weight. One study that assessed the long-term effectiveness of a schoolbased education program 10 years after its initiation found promising results regarding body weight and body mass index (BMI) [36]. These assessments suggest that schools have been making some progress, but it is difficult to separate the impact of the education component from the policy and environmental change that is also included in these public health programs [37].

\section{Workplace}

Individuals spend up to $60 \%$ of their waking hours in their place of work and obesity in the workplace is an important driver of costs associated with absenteeism, sick leave, disability, injuries, and health care claims [38]. However, many workplaces work against better weight control as they provide a sedentary setting with access to energy-dense food and beverages. It is therefore not surprising that studies have shown associations between greater BMI and long work hours, shift work, and job stress [39]. Thus, the workplace is a prime setting to encourage healthy dietary practices and increase activity [40]. Workplace interventions may involve informational and behavioral strategies and/or environmental modification, but programs promoting healthy eating have largely focused on individual responsibility (education and behavior change). Overall, evidence shows that multicomponent worksite programs that target nutritional and physical behaviors confer modest, positive, weight-related benefits on participants. The results of a meta-analysis found positive effects at 6-12 months follow-up with a pooled effect among nine randomized controlled trials (RCTs) of -2.8 pounds $(95 \%$ confidence interval $[\mathrm{CI}],-4.6,-1.0)$ and decrease in BMI of $-0.5(95 \% \mathrm{CI},-0.8,-0.2)$ based on six RCTs [41•]. Most of the programs used a variety of strategies; thus it was difficult to show differential effects by program component but further analysis suggested that informational or educational approaches alone were less effective than those that added behavioral counseling and policy or environmental changes.

\section{Health Care}

Primary care has played a key role in the delivery of public health campaigns to reduce tobacco and alcohol consumption $[16,42]$ and recent evaluations of health education interventions in primary care settings have shown some positive impacts on dietary intake, physical activity, and weight [43, 44]. Assuncao et al. [43] randomly allocated patients to a nutritional care (education intervention) $(n=120)$ or usual care group $(n=121)$ and found that both groups presented statistically significant reductions in weight, BMI, and waist circumference at 6 months. However, compared with the usual care group (C), those in the intervention group (I) had higher physical activity levels (I: $+1.5 \mathrm{~h}$; C:-40 $\mathrm{min}$ ) and reduced intakes of sweet foods (I: $-44 \mathrm{~g} ; \mathrm{C}:-11 \mathrm{~g}$ ) at 6 months. Using a much smaller sample size $(n=34)$ and time frame ( 3 months), Peterson et al. [44] found that an education program among patients with type 2 diabetes resulted in reductions in body weight $(81.3 \pm 17.9 \mathrm{~kg}$ vs $80.3 \pm 18.0 \mathrm{~kg})$, waist circumference $(101.6 \pm 13.4 \mathrm{~cm}$ vs $99.1 \pm 12.7 \mathrm{~cm})$, and truncal fat $(16.5 \pm 5.7 \mathrm{~kg}$ vs $15.9 \pm 5.6 \mathrm{~kg})$.

It is evident that health education interventions in primary care offer some promise; however, interventions have generally been short-lived and will require much longer maintenance and more detailed evaluations [45, 46]. Little is known about the cost-effectiveness of such interventions and more research is needed on collaborative interventions so that health workers have the support and capacity to coordinate multicomponent interventions [46]. Implementation of such interventions should involve expanding the skills of existing health professionals [16].

\section{Community}

Community-level interventions target large sections of the community, neighborhoods, families, or disadvantaged populations and engage government and nongovernment organizations and commercial groups [16]. Public health programs dealing with road safety, immunization, and tobacco have successfully utilized community-based approaches to achieve behavior change and health improvement outcomes [47]. Community-based nutrition and physical activity programs 
show that it is possible to deliver programs to a wide segment of the population and achieve some behavior change; but to date, there is little evidence of successful community-wide weight gain prevention interventions, and limited evidence from smaller targeted interventions. Disadvantaged groups of the community are often the target of many education strategies, but such interventions depend heavily on uptake and participation in strategies or process evaluation.

Cooking skills are a fundamental part of dietary education, particularly for disadvantaged groups who may lack the skills or knowledge to prepare and cook healthy meals. Few studies have evaluated budgeting or cooking programs among communities; however, a recent review indicates positive dietary changes among such programs [48]. Community gardens permit community members to develop the skills and knowledge to grow and harvest their own fresh produce, especially if conducted with an education component [16]. Again, there has been little evaluation of the impact of these interventions; however, Kuipers [48] indicates that community gardens may increase fruit and vegetable consumption among growers. Community healthy weight programs have been shown to reduce body weight among lower socioeconomic groups [49]; however, it has been indicated that although a single health education lesson may result in weight loss, more interactive behavioral interventions would be associated with greater reductions in weight and maintenance of weight [50].

Certain characteristics of community-based programs may limit their evaluation. Community-based programs take considerable time to develop and implement and programs are usually conducted in partnership with a number of key community stakeholders. Although the involvement of different sectors and settings is key to sustaining interventions, the diversity of such programs makes comparison of programs difficult and detecting change in weight status is likely to take many years to achieve [16].

\section{Why Are Public Health Education Programs Ineffective at Addressing Obesity?}

There are a number of reasons why current public health education programs have failed to have an impact on the increasing prevalence of obesity. First, education programs have often failed to acknowledge the limitations of health education or the complex relationship between health communication and behavior change and have not based their strategies on sound theories of behavior change. Second, the complicated nature of obesity and the complex array of interrelated factors that influence weight-related behaviors and drive the increasing prevalence of obesity mean that education alone is unlikely to be sufficient to achieve appropriate behavior change and reduce or control weight.
Third, it has been suggested that the public has an increasing distrust toward health professionals and may be becoming more reluctant in accepting public health campaigns [51]. Lastly, the lessons learned from past public health campaigns about intensity, breadth, and duration of action required to achieve and maintain behavior change have not been applied.

\section{Use of Communication and Behavior Change Theory}

Past public health education campaigns have often focused too much on developing sophisticated communication methods while failing to address the complex relationship between communication and behavior change. Basing communication campaigns on health behavior theory ensures that these issues are addressed. Many theories of health behavior change including the Health Belief Model and Social Cognitive Theory recognize that knowledge is a necessary element of behavior change and the PRECEDEPROCEDE (Predisposing, Reinforcing, and Enabling Constructs in Educational Diagnosis and Evaluation-Policy, Regulatory, and Organizational Constructs in Educational and Environmental Development) model emphasizes the importance of educational interventions as they can influence predisposing, reinforcing, and enabling factors [52]. Thus, it is not surprising that theory-based campaigns and programs offer the most promise in influencing behavior change $[53,54]$.

However, the primary objective of many health communication campaigns is to improve health literacy - the ability to access, understand, and apply health knowledge - rather than directly influence behavior. Despite the assumed close link there has been surprisingly little evaluation of the impact of health literacy programs on health behavior change or on weight status. A recent review of consumer's response to dietary guidelines reported that many consumers found such guidelines confusing, and this raises questions as to whether this lack of clarity and cognizance interferes with the behavior change such guidelines are intended to promote [55]. At the same time, studies that have evaluated the impact of health education in a more general context on behavior change and health outcome often overlook the mediatory role that health literacy has on such outcomes.

\section{The Ability of Public Health Education to Address} the Drivers of Obesity

As our understanding of the causes of obesity has grown, so has the acceptance of the limitations of obesity prevention and management strategies based on education alone. Several analyses have attempted to define the key determinants of obesity and, although there remains a degree of controversy 
over which factors have made the greatest contribution to the recent rise in the rates of obesity, the breadth of influences over body weight are becoming clearer. It is now accepted that physiologic "energy regulation" mechanisms operate within each person to keep weight and body fat stores stable in the long term. However, powerful societal and environmental forces influence energy intake and expenditure through effects on dietary and physical activity patterns, and may overwhelm the physiologic control of body weight. The susceptibility of individuals to these forces is influenced by psychological factors such as self-esteem, stress, individualism, and peer pressure, as well as genetic and other biological factors such as gender, age, and hormonal activities, over which they have little or no control [56].

Because biological variations cannot be addressed by public health action, focus has now shifted to the societal and environmental factors that influence key nutrition and physical activity behaviors in an attempt to improve the success of obesity control programs that utilize health education. Recently, the Foresight Programme of the UK Government Office for Science used a systems approach to produce a complex conceptual model with 108 variables known as the "obesity systems map" [57]. The relationships between the variables are illustrated with more than 300 solid or dashed lines to indicate positive and negative influences. All the variables are interconnected and these connections give rise to feedback loops. At the core (or engine) of the map is energy balance surrounded by variables that directly or indirectly influence this key process. The foresight map has been criticized for being for being overly complex to the extent that it creates a sense of confusion and despair when clarity is what is needed to address this problem. However, it has served its purpose by creating awareness of the need to address the array of forces that operate at the different layers of society that impact directly or indirectly upon food and physical activity behaviors.

Learning the Lessons from Past Public Health Action

The lack of large-scale, well-evaluated public health obesity programs that have been successful at controlling weight within a population has led many commentators to distill lessons from other successful public health initiatives. Such an approach can provide valuable lessons to improve the effectiveness of public health action to address obesity but care must be taken to interpret the nature of this parallel evidence, and the context in which these actions occurred, to ensure that the learning is applied correctly. Tobacco control has been lauded as one of the great public health success stories and a number of analyses of the success of action on smoking have been published $[42,58]$. These analyses have indicated that public health messages were extremely important in improving awareness about the health issues around smoking and in helping to shape social norms that enabled widespread behavior change. However, education alone is not sufficient to facilitate and enable behavior change. It must be accompanied by a comprehensive range of actions. Similar lessons emerged from public health programs to address seat belt use, alcohol and driving, breastfeeding, and vaccinations [3, 59]. Successful public health education campaigns involved mass communication that included consistent, positive messages, supported by scientific consensus that were repeated in a variety of formats and venues. They were complemented by a range of advocacy, regulatory, policy, and environmental changes that promoted healthy behaviors and a plan that included many components that worked synergistically [3].
Fig. 1 Effective obesity prevention campaigns are multicomponent and go beyond education alone. PE-physical education
Schools/child care

- Healthy school canteens

- Support and fund PE and sports

- Vending machines

- School sponsorships

\section{Urban design}

- Protect open spaces

- Pedestrian precincts, bike paths

- Links with public transport

\section{Transport}

- Expand and support public transport and active transport

\section{Food industry}

- Healthy food choices

- Portion sizes

- Food labeling

- Public health education campaigns underpinning other strategies

- Regulation of food marketing to children

- Promotion of fruits and vegetables

Work sites

- Healthy food choices

- Physical activity opportunities

\section{Health care}

\section{Supporting families}

- Parenting support

- Healthy food and activity environments in child care

- Health professional training

- Coordinated health service delivery

- Funding for services 


\section{Successful Public Health Action on Obesity}

More recent community-wide obesity prevention programs have learned the lessons and have developed multicomponent strategies that go beyond education and attempt to address some of the key policy and environmental factors that inhibit appropriate behavior change (Fig. 1). Multicomponent programs aimed at preventing excessive weight gain in school-aged children have produced positive results in communities in the United States [60], Australia [61], and in France [62], although the absolute reductions in BMI or other measures of adiposity remain modest at present. The largest of these programs, the EPODE (Ensemble, Prévenons l'Obésité des Enfants) campaign, is a community initiative launched in January 2004 in 10 towns in France targeted at children ages 5-12 years. The program works by engaging local policy makers and key organizations within each town to support and drive a stepwise series of educational opportunities, food supply changes, and exercise activities for children in their everyday life. The participation rate has grown quickly and in 2009 the program involved 1.8 million children in 167 French, 20 Spanish, and 8 Belgium cites. The French component was evaluated by a series of repeated cross-sectional surveys and indicated a fall in the level of overweight and obesity in these towns from $18.9 \%$ in 2004 to around $17 \%$ in 2007 [62].

\section{Conclusions}

Public education and communication has been a central element of a number of successful past public health campaigns to address issues such as tobacco control, alcohol use, and road safety. Public health messages were presented through mass media, government and health care systems, and through education in a number of settings. The advent of new media has allowed new opportunities to distribute health information and target specific demographics. Health education and broad media communication have also been utilized to stimulate behavioral change to prevent and reduce obesity. However, analyses suggest that education alone is unlikely to achieve the level of behavioral change necessary to address weight status. It is now clear that a much more comprehensive program of public health action will be required to not only improve knowledge and attitudes, but to also address many of the policy and environmental factors that influence our ability to make the level of nutrition and physical activity behavior change necessary to control weight.

Disclosure Conflicts of interest: T.P. Gill: has received grant support from the Australian Department of Health and Ageing; S. Boylan: none.

\section{References}

Papers of particular interest, published recently, have been highlighted as:

- Of importance

•- Of major importance

1. •- Kopelman P. Symposium 1: Overnutrition: consequences and solutions. Foresight Report: the obesity challenge ahead. Proc Nutr Soc 2010;69:80-85. This paper discusses the main issues raised by the UK Foresight Report for effectively tackling obesity at a population level and examines the implications for all sectors of society.

2. Abegunde DO, Mathers CD, Adam T, et al. The burden and costs of chronic diseases in low-income and middle-income countries. Lancet. 2007;370:1929-38.

3. Economos CD, Brownson RC, DeAngelis MA, et al. What lessons have been learned from other attempts to guide social change? Nutr Rev. 2001;59:S40-56.

4. Haslam DW, James WP. Obesity. Lancet. 2005;366:1197-209.

5. Noar SM. A 10-year retrospective of research in health mass media campaigns: where do we go from here? J Health Commun. 2006; 11:21-42

6. Steckler A, Allegrante JP, Altman D, et al. Health education intervention strategies: recommendations for future research. Health Educ Q. 1995;22:307-28.

7. Gill T, King L, Caterson I. Obesity prevention: necessary and possible. A structured approach for effective planning. Proc Nutr Soc. 2005;64:255-61.

8. Arem H, Irwin M. A review of web-based weight loss interventions in adults. Obes Rev. 2011;12:236-43.

9. Neve M, Morgan PJ, Jones PR, Collins CE. Effectiveness of webbased interventions in achieving weight loss and weight loss maintenance in overweight and obese adults: a systematic review with meta-analysis. Obes Rev. 2010;11:306-21.

10. Gerber BS, Stolley MR, Thompson AL, et al. Mobile phone text messaging to promote healthy behaviors and weight loss maintenance: a feasibility study. Health Informatics J. 2009;15:1725.

11. Haapala I, Barengo NC, Biggs S, et al. Weight loss by mobile phone: a 1-year effectiveness study. Public Health Nutr. 2009;12:2382-91.

12. Kornman KP, Shrewsbury VA, Chou AC, et al. Electronic therapeutic contact for adolescent weight management: the Loozit study. Telemed J E Health. 2010;16:678-85.

13. Turner-McGrievy GM, Campbell MK, Tate DF, et al. Pounds off digitally study: a randomized podcasting weight-loss intervention. Am J Prev Med. 2009;37:263-9.

14. Block JP, Chandra A, McManus KD, Willett WC. Point-ofpurchase price and education intervention to reduce consumption of sugary soft drinks. Am J Public Health. 2010;100:1427-33.

15. Sacks G, Tikellis K, Millar L, Swinburn B. Impact of 'traffic-light' nutrition information on online food purchases in Australia. Aust N Z J Public Health. 2011;35:122-6.

16. Gill TP. A "state of the knowledge" assessment of comprehensive interventions that address the drivers of obesity. Sydney: National Health and Medical Research Council; 2011.

17. Technomic Inc. Update: consumer reaction to calorie disclosure on menus/menu boards in New York City. Chicago: Technomic Inc; 2009. Available at: http://www.edhoman.com/public/files/HB7833.pdf. Accessed September 2011

18. Kuo T, Jarosz CJ, Simon P, Fielding JE. Menu labeling as a potential strategy for combating the obesity epidemic: a health impact assessment. Am J Public Health. 2009;99:1680-6. 
19. Elbel B, Kersh R, Brescoll VL, Dixon LB. Calorie labeling and food choices: a first look at the effects on low-income people in New York City. Health Aff (Millwood). 2009;28:1110-21.

20. - Dumanovsky T, Huang CY, Nonas CA, et al. Changes in energy content of lunchtime purchases from fast food restaurants after introduction of calorie labelling: cross sectional customer surveys. BMJ 2011;343:4464. This paper evaluates the impact of the New York City calorie labeling regulations for fast food restaurants but also contains some useful discussion on what it takes to achieve behavior change. There is a useful commentary and responses to this article in the same journal.

21. Mullen PD, Evans D, Forster J, et al. Settings as an important dimension in health education/promotion policy, programs, and research. Health Educ Q. 1995;22:329-45.

22. Gluckman PD, Hanson MA, Cooper C, Thornburg KL. Effect of in utero and early-life conditions on adult health and disease. N Engl J Med. 2008;359:61-73.

23. Ronnberg AK, Nilsson K. Interventions during pregnancy to reduce excessive gestational weight gain: a systematic review assessing current clinical evidence using the Grading of Recommendations, Assessment, Development and Evaluation (GRADE) system. BJOG. 2010;117:1327-34.

24. Dodd JM, Grivell RM, Crowther CA, Robinson JS. Antenatal interventions for overweight or obese pregnant women: a systematic review of randomised trials. BJOG. 2010;117:1316-26.

25. Arenz S, Ruckerl R, Koletzko B, von Kries R. Breast-feeding and childhood obesity - a systematic review. Int J Obes Relat Metab Disord. 2004;28:1247-56.

26. Hector D, Hebden L, Innes-Hughes C, King L. Update of the evidence base to support the review of the NSW Health Breastfeeding Policy: a rapid appraisal. Sydney: PANORG; 2010.

27. - Story M, Nanney MS, Schwartz MB. Schools and obesity prevention: creating school environments and policies to promote healthy eating and physical activity. Milbank Q 2009;87:71-100. This article reviews the role of schools in obesity prevention by examining current issues and policies within the school environment. It also discusses the actions required to accelarate positive change.

28. Chavez FC. Evaluation of the T.O.D.A.Y project: the impact of a diabetes and obesity school-based prevention program on the behavior and knowledge of 5th grade students. San Diego: San Diego University; 2010.

29. Jan S, Bellman C, Barone J, et al. Shape it up: a school-based education program to promote healthy eating and exercise developed by a health plan in collaboration with a college of pharmacy. J Manag Care Pharm. 2009;15:403-13.

30. Moore JB, Pawloski LR, Goldberg P, et al. Childhood obesity study: a pilot study of the effect of the nutrition education program Color My Pyramid. J Sch Nurs. 2009;25:230-9.

31. Shah P, Misra A, Gupta N, et al. Improvement in nutritionrelated knowledge and behaviour of urban Asian Indian school children: findings from the 'Medical education for children/Adolescents for Realistic prevention of obesity and diabetes and for healthy aGeing' ( MARG) intervention study. Br J Nutr. 2010;104:427-36.

32. Tse MM, Yuen DT. Effects of providing a nutrition education program for teenagers: dietary and physical activity patterns. Nurs Health Sci. 2009;11:160-5.

33. Craven KW, Moore JB, Swart AS, et al. School-based nutrition education intervention: effect on achieving a healthy weight among overweight ninth-grade students. J Public Health Manag Pract. 2011;17:141-6.

34. Cullen KW, Lara Smalling A, Thompson D, et al. Creating healthful home food environments: results of a study with participants in the expanded food and nutrition education program. J Nutr Educ Behav. 2009;41:380-8.
35. Fernandes PS, Bernardo Cde O, Campos RM, Vasconcelos FA. Evaluating the effect of nutritional education on the prevalence of overweight/obesity and on foods eaten at primary schools. J Pediatr. 2009;85:315-21.

36. Hatzis CM, Papandreou C, Kafatos AG. School health education programs in Crete: evaluation of behavioural and health indices a decade after initiation. Prev Med. 2010;51:262-7.

37. The Society for Nutrition Education. State of nutrition education and promotion for children and adolescents. Indianapolis: The Society for Nutrition Education; 2009. Available at: http://www. sne.org/documents/SNENENPreport630_Final.pdf. Accessed September 2011

38. Ostbye T, Dement JM, Krause KM. Obesity and workers' compensation: results from the Duke Health and Safety Surveillance System. Arch Intern Med. 2007;167:766-73.

39. Schulte PA, Wagner GR, Ostry A, et al. Work, obesity, occupational safety and health. Am J Publ Health. 2004;97:428-36.

40. Ni Mhurchu C, Aston LM, Jebbs SA. Effects of worksite health promotion interventions on employee diets: a systematic review. BMC Public Health 2010;10.

41. - Anderson LM, Quinn TA, Glanz K, et al. The effectiveness of workite nutrition and physical activity interventions for controlling employee overweight and obesity: a systematic review. Am J Prev Med 2009;37:340-357. This systematic review examines the effectiveness of worksite nutrition and physical activity programs in promoting healthy weight among employees. It also examines the economic efficiency of interventions and presents an analytical framework for worksite interventions to improve weight status.

42. Mercer SL, Green LW, Rosenthal AC, et al. Possible lessons from the tobacco experience for obesity control. Am J Clin Nutr. 2003;77:1073S-82S.

43. Assuncao MC, Gigante DP, Cardoso MA, et al. Randomized, controlled trial promotes physical activity and reduces consumption of sweets and sodium among overweight and obese adults. Nutr Res. 2010;30:541-9.

44. Peterson RM, Beeson L, Shulz E, et al. Impacting obesity and glycemic control using a culturally-sensitive diabetes education program in Hispanic patients with type 2 diabetes. Int $\mathrm{J}$ Body Compos Res. 2010;8:85-94.

45. Lagger G, Pataky Z, Golay A. Efficacy of therapeutic patient education in chronic diseases and obesity. Patient Educ Couns. 2010;79:283-6.

46. Tsai AG, Wadden TA. Treatment of obesity in primary care practice in the United States: a systematic review. J Gen Intern Med. 2009;24:1073-9.

47. Kumanyika S, Jeffery RW, Morabia A, et al. Obesity prevention: the case for action. Int J Obes Relat Metab Disord. 2002;26:42536.

48. Kuipers Y. Focusing on obesity through a health equity lens: a collection of innovative approaches and promising practices by European and international health promotion bodies to counteract obesity and improve health equity: EuroHealthNet; 2010.

49. Martin PD, Rhode PC, Dutton GR, et al. A primary care weight management intervention for low-income African-American women. Obesity. 2006;14:1412-20.

50. Lombard CB, Deeks AA, Ball K, et al. Weight, physical activity and dietary behavior change in young mothers: short term results of the HeLP-her cluster randomized controlled trial. Nutr $\mathrm{J}$. 2009;8:17.

51. Crossley M. Resistance to health promotion: a preliminary comparative investigation of British and Australian students. Health Education. 2002;102:289-99. 
52. Green LW, Kreuter MW, Deeds S, Partridge K. Health education planning: a diagnostic approach. California: Mayfield; 1980.

53. Orleans T. Foreward. In: Glanz K, Rimer BK, Viswanath K, editors. Health behavior and health education. San Francisco: Jossey-Bass; 2008. p. xiii-xv.

54. Randolph W, Viswanath K. Lessons learned from public health mass media campaigns: marketing health in a crowded media world. Annu Rev Public Health. 2004;25:419-37.

55. Boylan SM, Louie JCY, Gill TP. Consumer response to weightrelated recommendations: a systematic review. Obes Rev. 2012, In press.

56. World Health Organisation. Joint WHO/FAO expert report on diet, nutrition and the prevention of chronic disease. Geneva: World Health Organisation; 2003.

57. Butland B, Jebb S, Kopelman P, et al. Foresight: Tackling Obesities: Future Choices Project Report 2nd edition. UK: Goverment Office for Science; 2007.
58. Centre for Disease Control and Prevention. Best practices for comprehensive tobacco control programs-2007. Atlanta: Centre for Disease Control and Prevention; 2007.

59. Gilmore I. What lessons can be learned from alcohol control for combating the growing prevalence of obesity? Obes Rev. 2007;8 Suppl 1:157-60.

60. Economos CD, Hyatt RR, Goldberg JP, et al. A community intervention reduces BMI z-score in children: Shape Up Somerville first year results. Obesity. 2007;15:1325-36.

61. Sanigorski AM, Bell AC, Kremer PJ, et al. Reducing unhealthy weight gain in children through community capacity-building: results of a quasi-experimental intervention program, Be Active Eat Well. Int J Obes. 2008;32:1060-7.

62. Summerbell CD, Moore HJ, Borys JM, et al. Prevalence of overweight and obesity in serial cross-sectional surveys of the Ensemble, Prévenons l'Obésité des Enfants (EPODE) campaign. Obesity Facts 2009:119-120. 